\title{
Antioxidant Properties and Total phenolic content of herbs used in post partum diet therapy in Patna (Bihar), India
}

\author{
Shadma Shahin ${ }^{1}$ and Naheed Ahmad ${ }^{2}$ \\ Departmentof Botany, Patna University, Patna (Bihar), India
}

\begin{abstract}
The traditional medicinal system of India offers a detailed diet therapy for post partum health care to rejuvenate women's health. The minority community in Patna(Bihar) uses selected herbs as traditional recipes for post partum health care. Current study was designed to investigate pharmacological studies to validate folk use of such herbal recipes.All plants were tested for DPPH,FRAP AND total phenolic content. The investigation showed significant therapeutic effect of folk medicinal recipes used as traditional post partum care .
\end{abstract}

Keywords:Patna, DPPH,FRAP, Phenols, Postpartum care.

\section{I.Introduction}

Antioxidant with free radical scavenging activities may have great relevance in the prevention and therapeutics of diseases in which oxidants ${ }^{1}$ or free radicals are implicated currently,the possible toxicity of synthetic antioxidants has been criticized . Thus interest in natural antioxidants, especially of plant origin, has greatly increased in recent year. ${ }^{2}$ Plants may contain a wide variety of free radical scavenging molecules, such as phenolic compounds, (e.g.phenolic acids, flavonoids quinones, coumarins, lignans, stilbenes, tanins), terpenoids(inlcuding carotenoids), and some other endogenous metabolites, which are rich in antioxidant activity. ${ }^{3}$ Epidemiological and invitro studies suggested that plants are major constituent in antioxidant based drugs/ formulations used for the prevention of complex diseases. ${ }^{4}$ The use of herbs in traditional way is becoming revitalized over the world. More over since modern medicine in becoming more wide spread but at a high cost. In rural area, it is useful in certain case like surgery. Traditional medicine still plays an important role and commonly used as primary form of health care for people especially in critical events such as in post partum care of women. In many south east Asian cultures post partum period is considered important from point of view of recovery, by offering a period of confinement ranging from 10 to 45 days. Many behavioral and dietary restrictions are followed during this period. Diet therapy includes preparations of medicinal herbs in the form of decoctions, infusions and cold extracts. The herbs given during this period are traditionally known to strengthen the body and mind and prevent disorder such as a post partum depression (PPD), insomnia, body aches indigestion, and oxidative stress. ${ }^{5}$ The diet is also helpful for growth and development of new born as bioactive molecules pass from mother to child through lactation. This study was then designed to test antoxidation and to determine total phenolic contents of selected herbs, used in diet therapy after parturition in postpartum care in Patna.

\section{II.1. Plant Material}

\section{Material And Methods}

The plant samples were obtained from the medicinal plant traders and identified in the laboratory based on local name and pharmacognosy.

\section{II.2. Chemicals And Instruments}

Folin-Ciocalteu's phenol reagent, gallic acid, anhydrous sodium carbonate, ethyl alcohol, methanol, 2,2-di pheny-1-Picryhydrazyl (DPPH) were of analytical grade and procured from local sources.

\section{II.3. Sample Collection And Extraction}

Ten species of herbs, commonly used in postpartum care were selected for the study. Each sample was collected from three outlets, which were pooled and considered as single sample. Each sample was extracted and analyzed in triplicates. One hundred gram of dry ground plant material was macerated in $70 \%$ ethyl alcohol shaken for five hours then kept at room temperature for 24 hours in closed containers. The extraction process was repeated three times. Then the extracts were filtered under vacuum and concentrated at reduced pressure using a rotary evaporator. The dried extracts were kept in the refrigerator at $4^{0} \mathrm{C}$ until use. 


\section{II.4. Determination Of Total Phenolic Content}

The amount of total phenolics in extracts was determined with the Folin- Ciocalteu reagent. Gallic acid was used as a standard and the total phenolics were expressed as $\mathrm{mg} / \mathrm{g}$ gallic acid equivalents (GAE) ${ }^{4}$. Concentration of $0.01,0.02,0.03,0.04$ and $0.05 \mathrm{mg} / \mathrm{ml}$ of gallic acid were prepared in methanol. Concentration of 0.1 and $1 \mathrm{mg} / \mathrm{ml}$ of plant extract were also prepared in methanol and $0.5 \mathrm{ml}$ of each sample were introduced into test tubes and mixed with $2.5 \mathrm{ml}$ of a 10 fold dilute Folin- Ciocalteu reagent and $2 \mathrm{ml}$ of $7.5 \%$ sodium carbonate. The tubes were covered with parafilm and allowed to stand for 30 minutes at room temperature before the absorbance was at read at $760 \mathrm{~nm}$ spectrophotometrically. All determination was performed in triplicate. The Folin-Ciocalteu reagent is sensitive to reducing compounds including polyphenols, thereby producing a blue colour upon reaction. This blue colour is measured spectrophotometrically. Thus total phenolic content can be determined ${ }^{6-7}$.

\section{II.5. DPPH Radical-Scavenging Activity}

DPPH radical-scavenging activity was determined according to Aoshimaet al. ${ }^{8}$ This method is based on the ability of the antioxidant to scavenge the DPPH cation radical. Briefly, to $100 \mu \mathrm{L}$ of sample extract or standard, $2.9 \mathrm{~mL}$ of DPPH reagent $(0.1 \mathrm{mM}$ in methanol) was added and vortexed vigorously. This was allowed to stand in dark for 30 min at room temperature, and the discoloration of DPPH was measured against a suitable blank at $517 \mathrm{~nm}$. Percentage inhibition of the discoloration of DPPH by the sample extract was expressed as Trolox equivalents $(\mathrm{mg} / 100 \mathrm{~g})$.

\section{II.6. FRAP Assay}

Ferric reducing antioxidant power (FRAP) was determined according to Benzie and Strain ${ }^{9}$. In the presence of TPTZ, the Fe+2-TPTZ complex exhibits blue color which is read at $593 \mathrm{~nm}$. Briefly, $3.0 \mathrm{~mL}$ of working FRAP reagent was added to an appropriate volume/concentration of the sample extract, incubated for 6 min at room temperature, and the absorbance was measured at $593 \mathrm{~nm}$ against $\mathrm{FeSO} 4$ standard.

\section{II.7. Statistical Analysis}

All the data were recorded in triplicate $(n=3)$ and results have been expressed as mean \pm standard deviation. To correlate the results obtained with different methods, a regression analysis was performed and correlation coefficients were calculated.

\section{Results And Discussion}

The amount of total phenolics measured by folin-Ciocalteu method varied widely in herbal materials and ranged from 3.86 to $635.28 \mathrm{GAE} / \mathrm{g}$ dry weight (dw) Table (i). The highest level of phenolics was found in Quercus infectoria, while lowest was in Asparagus racemosus. Herbs like Butea monospherma, Terminalia .chebula, showed a highest phenolic content of 416.56, $156 \mathrm{mg} \mathrm{GAE} / \mathrm{g}$ of sample, respectively. Among the selected herbs Asparagus recemosus and Piper longum showed a very low phenolic content (3.86 and $4.11 \mathrm{mg}$ GAE/g respectively). DPPH radical scavenging activities of herbs varied from 21.19 to $89.19 \%$. Quercus infectoria extract showed highest antioxidant capacity $(89.19 \%$ of DPPH inhibition, followed by Trachyspermum ammi, Butea monosperma, myrtricsica fragrans and Zingiber officinales, which all are also showed in $85 \%$ of DPPH inhibition. Among 10 sample 5 samples showed DPPH inhibition in the range of 80$90 \%$. Feric reducing antioxidant potential of plant extracts tested varied from $48 \mathrm{mM} \mathrm{Fe}^{+2} / \mathrm{g}$ to $1225 \mathrm{mMFe} \mathrm{e}^{+2} / \mathrm{g}$. Quercus infectoria (1225 $\left.\mathrm{mMFe}^{+2} / \mathrm{g}\right)$, Terminalia chebula $\left(1119 \mathrm{mMFe}^{+2} / \mathrm{g}\right)$, Myrtisica fragrans (599 $\left.\mathrm{mMFe}^{+2} / \mathrm{g}\right)$ showed very strong feric ion reducing activities. In this assay, Piper longum $\left(48 \mathrm{mMFe} \mathrm{F}^{+2} / \mathrm{g}\right)$ and Zingiber officniale ( $49 \mathrm{mMFe}^{+2} / \mathrm{g}$ ) showed the lowest feric reducing capacity. To correlate the results obtained with the different methods a regression analysis was performed (correlation coefficient, R). The results are shown in figures 1-3 and table 2. Correlation antioxidant potential were maximum between DPPH and FRAP $(\mathrm{R}=0.4345)$. The minimum correlation was found between DPPH and TPC $(\mathrm{R}=0.1015)$.It is noticed that the highest concentration of phenolic compound in the extracts were obtained using high polarity, the high content of phenolic compound and significant linear correlation between the values of the concentration and antioxidant activity indicated that these compounds contribute to the higher radical scavenging activity. Several herbs contain lower antioxidant activities in comparison to others. Folk use of these herbs may not necessarily be related to antioxidant activities, but for other purposes like stimulant and glactogogue properties. These herbs may also be consumed with different plant combination and act as bioenhancers. 
Antioxidant Properties and Total phenolic content of herbs used in post partum diet therapy in

\section{Figures And Tables}

Table -1:- Antioxidant capacity and total phenoliic content in 10 herbs used in diet thertapy during postpartum healthcare.

\begin{tabular}{|c|c|c|c|c|c|}
\hline Herb Name & Local Name & Part Used & $\begin{array}{l}\text { Total Phenolic } \\
\text { content (mg } \\
\text { GAE/gram) }\end{array}$ & $\begin{array}{l}\text { DPPH\% } \\
\text { inhibition }\end{array}$ & $\mathrm{FRAPmFe}+2 / \mathrm{g})$ \\
\hline $\begin{array}{l}\text { Asparagus recemosus } \\
\text { (Asparagaceae) }\end{array}$ & Shatavari & Roots & $3.86 \pm 0.32$ & $25.26 \pm 0.61$ & $70 \pm 1.16$ \\
\hline $\begin{array}{l}\text { Butea monosperma } \\
\text { (Fabaceae) }\end{array}$ & $\begin{array}{l}\text { Kamarkas } \\
\text { Palas }\end{array}$ & Gum & $416.56 \pm 7.28$ & $86.16 \pm 1.29$ & $76.0 \pm 1.28$ \\
\hline $\begin{array}{l}\text { Curcuma longa } \\
\text { (Zingiberaceae) }\end{array}$ & Haldi & Rhizome & $15.56 \pm 0.32$ & $75.35 \pm 1.25$ & $71 \pm 1.56$ \\
\hline $\begin{array}{l}\text { Embelia ribes } \\
\text { (Myrsinaceae) }\end{array}$ & $\begin{array}{l}\text { Vaividang/ } \\
\text { Babirang }\end{array}$ & $\begin{array}{l}\text { Fruits } \\
\text { (Berries) }\end{array}$ & $13.16 \pm 0.32$ & $69.57 \pm 0.71$ & $398 \pm 2.16$ \\
\hline $\begin{array}{l}\text { Myristica fragrans } \\
\text { (Myristicaceae) }\end{array}$ & Jaiphal & Seeds & $11.0 \pm 03$ & $85.89 \pm 1.58$ & $599 \pm 3.50$ \\
\hline $\begin{array}{l}\text { Piper longum } \\
\text { (Piperaceae) }\end{array}$ & Pipramul & Roots & $4.11 \pm 0.21$ & $43.47 \pm 0.10$ & $48 \pm 0.86$ \\
\hline $\begin{array}{l}\text { Quercus infectoria } \\
\text { (Fagaceae) }\end{array}$ & Majuphal & Galls & $635.25 \pm 9.3$ & $89.19 \pm 2.2$ & $1225 \pm 9.39$ \\
\hline $\begin{array}{l}\text { Terminalia chebula } \\
\text { (Combretaceae) }\end{array}$ & $\begin{array}{l}\text { Harad/ } \\
\text { Harre }\end{array}$ & Fruits & $156.0 \pm 0.33$ & $74.68 \pm 0.83$ & $1119 \pm 8.87$ \\
\hline $\begin{array}{l}\text { Trachyspermum ammi } \\
\text { (Apiaceae) }\end{array}$ & Ajwain & Seeds & $13.56 \pm 0.98$ & $86.29 \pm 1.01$ & $951 \pm 7.42$ \\
\hline $\begin{array}{l}\text { Zingiber officinale } \\
\text { (Zingiberaceae) }\end{array}$ & Saunth & Rhizome & $10.3 \pm 0.39$ & $85.12 \pm 0.51$ & $49 \pm 0.69$ \\
\hline
\end{tabular}

Table-2. Correlation Coefficient (R) between assays.

\begin{tabular}{lcc}
\hline & FRAP & DPPH \\
\hline DPPH & 0.4345 & \\
TPC & 0.3710 & 0.1015 \\
\hline
\end{tabular}

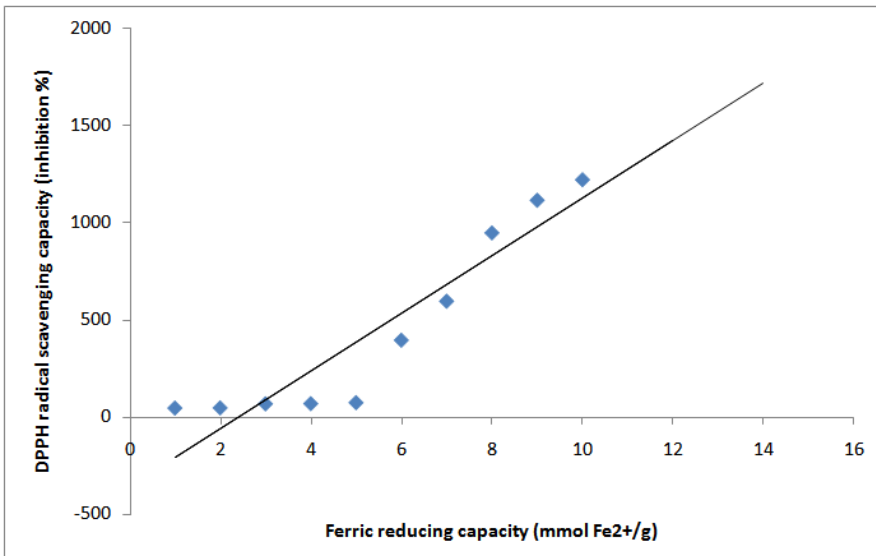

Fig. 1: Correlation between DPPH and FRAP assays. Correlation coefficient $\mathrm{R}=\mathbf{0 . 4 3 4 5}$

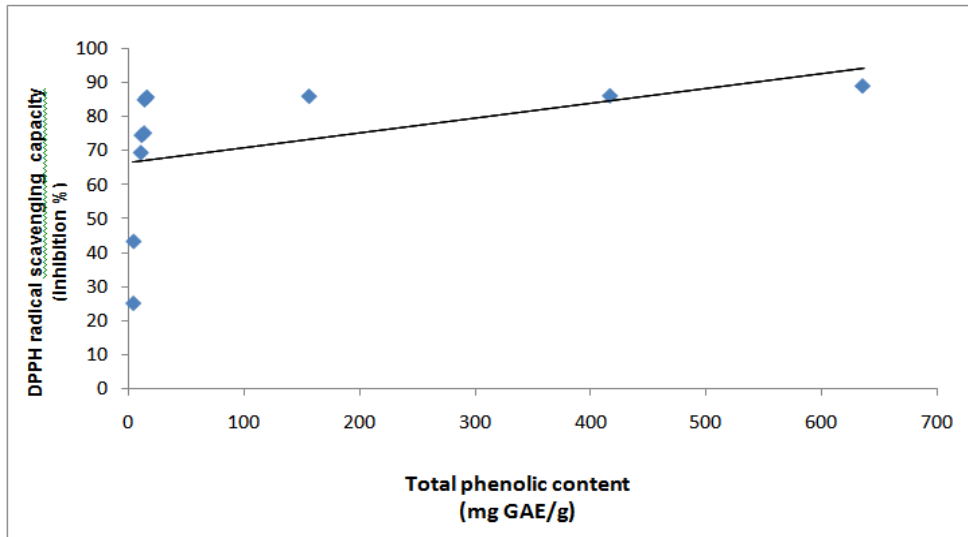

Fig. 2: Correlation between TPC and DPPH assays. Correlation coefficient $R=0.1015$ 


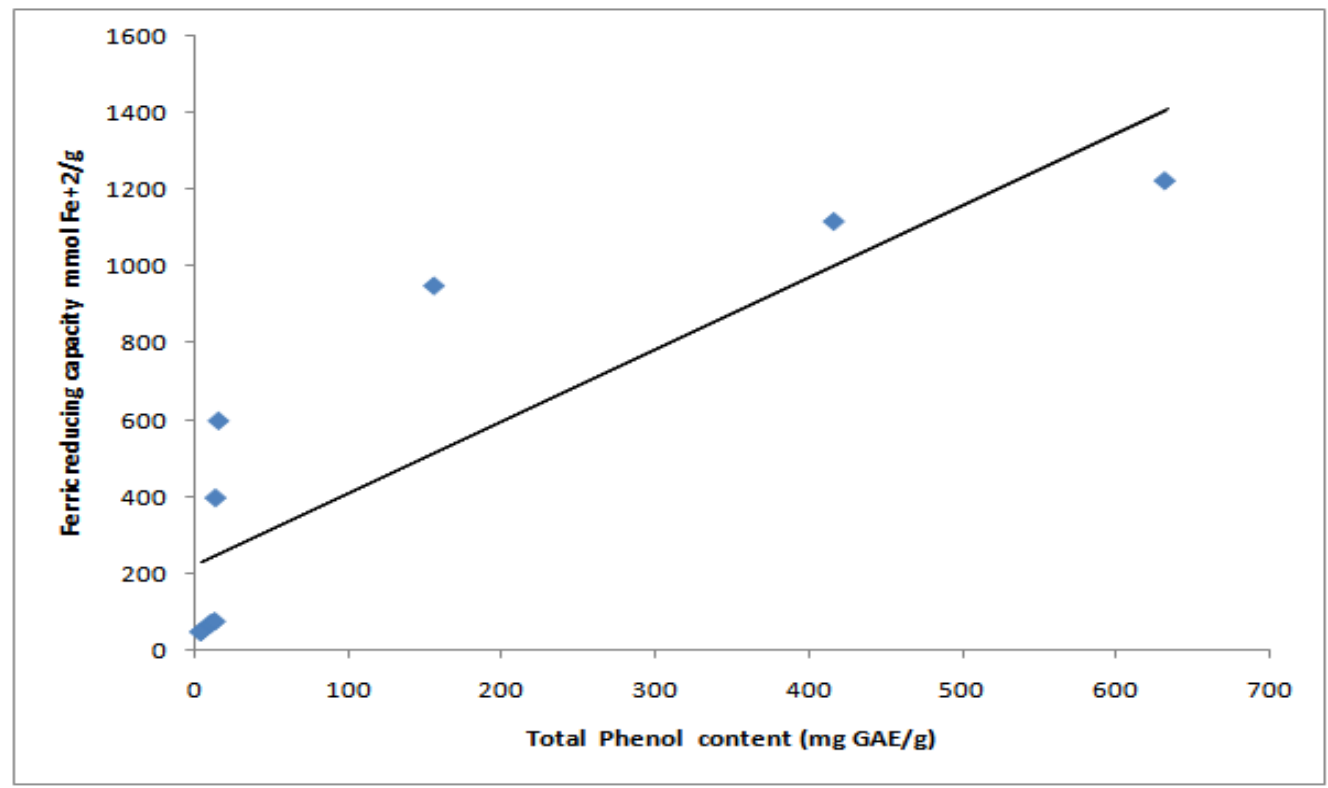

Fig. 3: Correlation between TPC and FRAP assays. Correlation coefficient $R=0.3710$

\section{Conclusion}

Results of our studies suggested that antioxidant properties of these herbs playing use in post natal recovery. The World Health Organization has also recognized the importance of traditional medicine and has created strategies and guide lines and standards for botanical medicine. Proven agroindustrial technologies need to be applied to the cultivation and processing of medicinal plants and the manufacture of herbal medicine. ${ }^{10}$ Based on this information it could be concluded that these herebs are natural sources of antioxidant substances of high importance.The investigation supports the folk use of these plants in post parturn care .

\section{Acknowledgement}

Financial support of the this work from the Department of Science and Technology (DST) Govt. of India is gratefully acknowledged.

\section{References}

[1] Soares JR, Dinis TCP, cunhaAp and Almedia LM, Antioxidant Activities of some Extract of Thymus zygis. Free Radical Research, (1997) 26: 469-478.

[2] Jayaprakash GK and Rao LJ, "Phenolic constituents from lichen ParmontremaStuppeum. Food Control (2000) 56: 1018-1022.

[3] Cai YZ, Sun M, CorkeH.Antioxidant activity of betalains from plant of the Amaranthaceae. J Agri C food Chem(2003); 54: 22882294.

[4] Kuo CC. Chaing W, Liu GP, Chien YL, Chang JY, etal. 2,2- Diphenyl-1-Picrylhydrazyl radical scavenging active components from adlay (Coixlacryma-JobiL.Varma-yuemstapf) hulls Agric food chem(2002), 50:5850-5855.

[5] Ku roda S, Watanabe M, Santo T, Shimizwishiy, Takano T.Et al, Post partum increase of serum thiaredoxine concentration and the relation to CDB lymphocytes. Analysis of Clinical Biochemistry (2010): 47: 62-66.

[6] Savitree M., Isara P., Nittaya S.L. and Worapan S., Radical Scavenging Activity and Total Phenolic Content of Medicinal Plants Used in Primary Health Care, Journal of Pharm. Sci., Vol. 9(1),(2004), Page No. 32-35

[7] Pourmorad F., Hosseinimehr S.J. and Shahabimajd N., Antioxidant activity, phenol and flavonoid contents of some selected Iranianmedicinal plants, African Journal of Biotechnology Vol.5 (11),(2006), Page No. 1142-1145.

[8] Aoshima H, Tsunoue H, Koda H, Kiso Y. Aging of whiskey increases 1,1-diphenyl-2-picrylhydrazyl radical scavenging activity. Journal of Agricultural and Food Chemistry.(2004);52(16):5240-5244.

[9] Benzie IFF, Strain JJ. Ferric reducing/antioxidant power assay: direct measure of total antioxidant activity of biological fluids and modified version for simultaneous measurement of total antioxidant power and ascorbic acid concentration. Methods in Enzymology. (1998);299:15-27.

[10] Rout SP, Choudary KA, Kar DM, Das L, Jain A. Plants in traditional medicinal system - future source of new drugs. Int J Pharm PharmSci(2009); 1:1-23. 